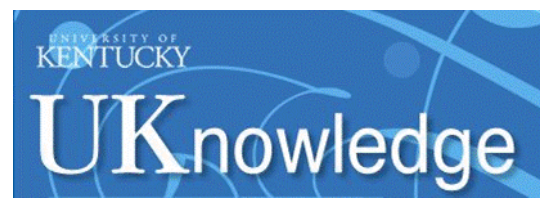

University of Kentucky

UKnowledge

$11-22-2016$

\title{
Correlates of Sexual-Risk Behaviors Among Young Black MSM: Implications for Clinic-Based Counseling Programs
}

\author{
Richard A. Crosby \\ University of Kentucky, richard.crosby@uky.edu \\ Leandro Mena \\ University of Mississippi Medical Center \\ JaNelle M. Ricks \\ The Ohio State University
}

Follow this and additional works at: https://uknowledge.uky.edu/healthbehavior_facpub

Part of the Counseling Commons, Feminist, Gender, and Sexuality Studies Commons, and the Public Health Commons

Right click to open a feedback form in a new tab to let us know how this document benefits you.

\section{Repository Citation}

Crosby, Richard A.; Mena, Leandro; and Ricks, JaNelle M., "Correlates of Sexual-Risk Behaviors Among Young Black MSM: Implications for Clinic-Based Counseling Programs" (2016). Health, Behavior \& Society Faculty Publications. 24.

https://uknowledge.uky.edu/healthbehavior_facpub/24

This Article is brought to you for free and open access by the Health, Behavior \& Society at UKnowledge. It has been accepted for inclusion in Health, Behavior \& Society Faculty Publications by an authorized administrator of UKnowledge. For more information, please contact UKnowledge@lsv.uky.edu. 
Correlates of Sexual-Risk Behaviors Among Young Black MSM: Implications for Clinic-Based Counseling Programs

Digital Object Identifier (DOI)

https://doi.org/10.1080/09540121.2016.1259449

Notes/Citation Information

Published in AIDS Care, v. 29, issue 6, p. 718-723.

(C) 2016 Informa UK Limited, trading as Taylor \& Francis Group

The copyright holder has granted the permission for posting the article here.

This is an Accepted Manuscript of an article published by Taylor \& Francis in AIDS Care on 22 Nov 2016, available online: http://www.tandfonline.com/10.1080/09540121.2016.1259449.

This article is available at UKnowledge: https://uknowledge.uky.edu/healthbehavior_facpub/24 
Published in final edited form as:

AIDS Care. 2017 June ; 29(6): 718-723. doi:10.1080/09540121.2016.1259449.

\title{
Correlates of sexual risk behaviors among young Black MSM: implications for clinic-based counseling programs
}

\author{
Richard A. Crosby, PhD ${ }^{1,2,3}$, Leandro Mena, $\mathbf{M D}^{3}$, and JaNelle Ricks, PhD \\ ${ }^{1}$ College of Public Health at the University of Kentucky, Lexington, KY, USA \\ ${ }^{2}$ Kinsey Institute for Research in Sex, Gender, and Reproduction, Bloomington, IN, USA \\ ${ }^{3}$ University of Mississippi Medical Center, Jackson, MS, USA \\ ${ }^{4}$ College of Public Health, Ohio State University,Columbus, OH, USA
}

\begin{abstract}
This study applied an 8-item index of recent sexual risk behaviors to young Black men who have sex with men (YBMSM) and evaluated the distribution for normality. The distribution was tested for associations with possible antecedents of sexual risk. YBMSM $(\mathrm{N}=600)$, ages 16-29 years, were recruited from an STI clinic, located in the Southern United States. Men completed an extensive audio-computer assisted self-interview. Thirteen possible antecedents of sexual risk, as assessed by the index, were selected for analyses. The 8-item index formed a normal distribution with a mean of 4.77 (sd=1.77). In adjusted analyses, not having completed education beyond high school was associated with less risk, as was having sex with females. Conversely, meeting sex partners online was associated with greater risk, as was reporting that sex partners were drunk during sex. The obtained normal distribution of sexual risk behaviors suggests a corresponding need to "target and tailor" clinic-based counseling and prevention services for YBMSM. Avoiding sex when partners are intoxicated may be an especially valuable goal of counseling sessions.
\end{abstract}

\section{Keywords}

Black/African American; men having sex with men; youth; HIV/AIDS; sexual behaviors

\section{Introduction}

Despite accounting for an estimated $2 \%$ of the United States population, men who have sex with men (MSM) account for an estimated three-fourths of all new HIV infections (CDC, 2015). Young, Black men who have sex with men (YBMSM) bear a substantially larger burden of new HIV infections any other sub-population in the nation (CDC, 2011; CDC, 2012; CDC, 2015; CDC, 2016a; Office of National AIDS Policy, 2010; Office of National AIDS Policy, 2015). Given a one-in-four chance of becoming infected with HIV by the time they reach 25 years of age (Black AIDS Institute, 2012), YBMSM are the highest priority population for intervention efforts (Office of National AIDS Policy, 2015). Further, given

Correspondence: Richard Crosby, PhD, College of Public Health, 111 Washington Ave. Lexington, KY 40506-0003; telephone: 502-370-5028 (ext 82039)/FAX: 859-323-2933/ crosbyr3@gmail.com. 
recent CDC estimates that 1 of every 2 Black MSM will acquire HIV in his lifetime (CDC, 2016b), an urgency exists to improve current intervention efforts for this population.

One promising venue for intervening with this often hard-to-reach population is within clinics that diagnose and treat sexually transmitted infections. Although standard counseling and education guidelines for patients attending STI clinics do not exist, several basic principles have been described that can guide this form of intervention (Crosby \& Meyerson, 2009). Two essential principles involve targeting (i.e., prioritizing persons most at-risk for intensified counseling/education) and tailoring (i.e., basing the session on changing the psycho-social antecedents of sexual risk behaviors). Thus, studies of a given population are optimally beneficial when they provide data pertaining to both targeting and tailoring (Crosby, Salazar, \& DiClemente, 2013; Salazar, Crosby, DiClemente, \& Noar, 2013).

Effective clinic-based counseling and education is also predicated on the basic observation that vastly different levels of sexual risk will exist within any given population (Crosby \& Meyerson, 2009). Although recognized as experiencing extreme risk of HIV acquisition, it is likely that sexual risk behaviors are widely varied within any one community of YBMSM. As is often true with any human population, behaviors are likely to be normally distributed. Existing literature suggests, however, that when assessed individually, sexual behaviors tend to be skewed and overdispersed (Mustanski et al., 2013; Safren et al., 2013; Burnham et al., 2016). Yet when considering sexual behavior in its totality, as an index of behavior for example, the distribution has a tendency to be normal (Laumann, Gagnon, Michael, \& Michaels, 1994). Thus, clinic-based intervention efforts for YBMSM cannot take a "one size fits all" approach (Chesney et al., 2003). Indeed, HIV risk behaviors may exist as a normal distribution thereby suggesting that corresponding clinic-based counseling and education efforts should be tailored based on: 1) level of risk (part of targeting) and 2) modifiable antecedents of sexual risk (part of tailoring). Identifying modifiable antecedent conditions and behaviors of sexual risk together is an especially important aspect of tailoring (Noar, Benac, \& Harris, 2007). Not all men in a given population of YBMSM will experience the same antecedent conditions or engage in the same level of antecedent behaviors (Koblin, Mayer, \& Eshleman, 2013).

The purpose of this study was to first create an index of recent sexual risk behaviors among YBMSM, to evaluate the distribution for normality, and to test the distribution for associations with possible antecedents of sexual risk.

\section{Methods}

\section{Study Sample}

A convenience sample of 600 young Black men who have sex with men were recruited for participation from a NIH-funded randomized controlled trial (RCT) of a safer sex intervention program designed specifically for this population. For the current study, only baseline data (collected before randomization and intervention) are presented. Participant recruitment occurred in a federally supported clinic designated for the diagnosis and treatment of HIV and other sexually transmitted infections. The clinic was located in a midsize southern city where incidence rates of HIV are particularly high. Inclusion criteria 
included: 1) assigned male at birth; 2) self-identification as Black/African American; 3) aged 15 to 29 years; 4) attending the clinic to be tested for HIV or other STIs, 5) having engaged in penile-anal sex with a male partner at least once in the past 6 months, and 6) the ability to speak and comprehend English.

All age-eligible Black men were approached in the clinic by research staff and asked about their interest in volunteering for an HIV prevention study. Those expressing interest were screened for eligibility. A total of 789 men were screened; of these, 623 were eligible. After being offered the opportunity to enroll, 14 declined, yielding an overall participation rate of $97.7 \%$. Nine of the enrolled men participated only as pilot subjects leaving a sample in the trial of 600 YBMSM. All study procedures were approved by the Institutional Review Boards of the University of Mississippi Medical Center, the Mississippi State Department of Health, and the University of Kentucky.

\section{Study Procedures}

After providing written informed consent (or parental consent for those under 18 years of age) participants completed an online questionnaire using Qualtrics $\odot$ (Provo, UT) in a private office not physically connected to the clinic. The questionnaire collected information relative to socio-demographic characteristics, sexual risk behaviors and sexual experiences.

\section{Self-Reported Measures}

Eight distinct sexual behaviors comprised the index used for this study. These items represent the universe of behaviors that occur among MSM which transmit sexual infection (Beyrer et al., 2012). Table 1 displays these items. In addition to common demographic factors (e.g., age, level of education, income), possible behavioral antecedents (Table 2) were selected based on the extant literature (Allen, Meyers, \& Ray, 2015; Benotsch, Kalichman, \& Cage, 2014; Kelly et al., 2013; Kelly et al., 2016; Maulsby et al., 2014; Mayer et al., 2014; Mimiaga et al., 2009; Mimiaga, et al, 2010; Morgan et al., 2015; Sifakis et al., 2010).

\section{Data Analysis}

A Pearson Product Moment Correlation of .01 ( $p=.79)$ was observed between men's age and the 8-item index; therefore, age adjustments were not deemed necessary. To determine associations between the index of sexual risk behaviors and the possible antecedents, a series of independent group t-tests were used to compare mean levels of the index score between men classified in the two groups on each of the 13 dichotomous measures displayed in Table 2. Finally, a hierarchical multiple linear regression model was tested to assess possible antecedents to sexual risk.

\section{Results}

\section{Sample Characteristics}

Mean age was 22.62 years, $(\mathrm{SD})=3.2$. An average monthly income of less than $\$ 1,000$ was reported by $46.1 \%$. The majority of participants $(58.6 \%)$ reported they were currently employed. More than one-half of the sample (59.8\%) reported having education beyond high 
school graduation and $47.3 \%$ reported current enrollment in a school or college. About onequarter of the men $(25.5 \%)$ were HIV-infected.

\section{Index of Sexual Risk Behaviors}

The distribution obtained from the 8-item index had a mean of $4.77(\mathrm{sd}=1.77)$ and ranged from 0 through 8 . The skewness ratio was 2.81 and the kurtosis ratio was .13. These relatively low values suggest normality. ${ }^{17}$ Figure 1 displays a histogram of the distribution.

As shown in Table 2, 10 of the 13 associations were significant. The three non-significant associations occurred for the measures of school enrollment, membership in a gay family, and attendance to religious services. These three measures were not evaluated further.

Findings from the hierarchical multiple linear regression model are displayed in Table 3 . The model was significant $(F=8.75, \mathrm{df}=6 / 575, p<.001)$. As shown, six variables remained in the stepwise model; however, two of these had $p$-values of .06 making those associations nonsignificant. Not having completed education beyond high school was associated with having a significantly lower score on the index of sexual risk behaviors, as was having sex with females. Conversely, meeting sex partners online was associated with significantly higher scores on the index, as was reporting that sex partners were drunk during sex.

Table 3 also displays significance levels for each of the interaction terms. As shown, only one antecedent (average monthly income of $<\$ 1,000$ ) had a significant interaction with HIV status. The obtained Beta estimate for this interaction term was -.13. The interaction was such that the protective effect of having a low income was only true for men who were HIVuninfected. Of $461 \mathrm{HIV}$-uninfected men, 199 (43.2\%) were classified as low income and their mean score on the index measure was 4.57. In contrast, the mean among those not classified as low-income was significantly greater at $4.88(t=2.51, d f=459, p=.01)$. The association between low-income and the index measure was non-significant among the 138 HIV-infected men $(t=.48, d f=136, p=.63)$.

\section{Discussion}

The obtained normal distribution of sexual risk behaviors has two clear implications. First, for clinicians, YBMSM are highly varied in the number of concurrently practiced sexual risk behaviors and this variance dictates a corresponding need to "target and tailor" counseling and prevention services. This brief index could be used as a diagnostic tool for the tailored counseling/education occurring in clinical settings. In terms of risk, these index items do not carry identical weights. Therefore, education and prevention strategies should be responsive to how particular items scored. Men reporting higher rates of condomless anal sex as a bottom with new partners who score in the upper one-half, for instance, may be triaged for more urgent and intensified services that promote PrEP use as well as intensified education sessions promoting the consistent and correct use of condoms. Evidence-based programs for the promotion of PrEP uptake and for condom use are available for YBMSM (Crosby, et al., 2009; Jones et al., 2008; Kalichman et al., 2005; Nostlinger et al., 2016), yet the time and resources involved in these one-to-one intervention programs may necessitate making decisions about who is prioritized for receipt of these counseling and education services. 
The second implication applies to researchers. The observed normal distribution of sexual risk behaviors suggests that measuring risk behavior with only one or two single items (e.g., frequency of condomless anal receptive sex) may misrepresent the true risk-level in any given population of YBMSM. Although intuitively an attractive option, single-item measures such a frequency of condomless sex fall short of providing meaningful information about the acquisition or transmission of HIV/STI simply because the behavior lacks context (e.g., number of partners with whom condomless sex occurred, the serostatus of the partner(s), whether partners were new partners). Without question, an idealized measurement schema would use event-level assessments to provide this necessary context; unfortunately, this method of assessment is labor-intensive for study participants, making survey burden a potential threat to the validity of self-reported data.

Findings regarding the possible antecedents of men's level of sexual risk have several implications for use in conjunction with the brief sexual behaviors index. These implications can be divided into two categories, with the first giving information about "who is most atrisk" (targeting) and the second giving information about antecedents that could be prioritized when tailoring clinic-based counseling and education for YBMSM (tailoring).

\section{Implications regarding targeting}

Regarding the first category, it is noteworthy that YBMSM having sex with females had significantly lower risk scores than their counterparts not having female sex partners. This association did not interact with men's HIV status thus suggesting that bisexually active YBMSM may be more moderate in their sexual risk-taking, regardless of whether they are HIV-infected. Also, that an education beyond high school was antecedent of elevated sexual risk is intriguing. Whether this effect is a product of those with greater levels of education having membership in sexual networks with riskier norms is a possibility warranting future investigation. Independently related, it was also observed that higher incomes (i.e., > $\$ 1,000$ per month) were associated with greater levels of sexual risk. The significant bivariate association with receipt of welfare did not retain significance in the presence of the variable representing a monthly income of $<\$ 1,000$; however the direction of association for each antecedent indicates that lower income may be related to yet-to-be determined factors that protect against sexual risk.

Further, the relatively greater level of risk-taking for men meeting sex partners online is interesting because it suggests that a possible underlying tolerance for sexual risk that may translate into the acquisition and transmission of HIV/STIs. That meeting sex partners online was retained in a multivariate model that tested ten possible antecedents intimates the possible utility of this behavior as a general marker for risk and thereby supports the concept of developing corresponding online approaches to the clinic-based promotion of safer sex for YBMSM. Emerging evidence suggests that making such online programs available through the same hook-up sites that men use may be efficacious (Chan et al., 2016).

Regarding the second category of antecedent findings (i.e., those giving information for tailored intervention efforts), the finding relative to men's sex partners being drunk during sex is especially novel and important. To this point, it is vital to bear in mind that study participants' use of alcohol during sex was not retained in the multivariate model and that 
two related measures were also not retained (use of illegal substances before sex and a separate measure of marijuana use before sex). This is consistent with existing literature demonstrating a weak association between being drunk or being high during sex and sexual risk behaviors among young Black men (Crosby et al., 2014). The independence of partner drunkenness thus suggests that the intoxication of partners may be one of the strongest antecedents of elevated sexual risk and therefore behavioral interventions designed for YBMSM may benefit this population by promoting responsible sex as including a sober partner. Intervention session components may also provide strategies to reduce the risk of engaging in sex with intoxicated partners as well as opportunities to practice these strategies through role-playing. Herein, however, lies a great disadvantage of using multiple regression to identify possible antecedents of sexual risk - the presence of one factor can overwhelm and thus mitigate the apparent importance of related factors (Keith, 2015). Thus, the bivariate findings relative to men's own use of alcohol, marijuana, or other substances before/during sex should not be readily dismissed as un-important.

\section{Limitations}

Beyond the inherent limitations of a convenience sample and the use of self-reported measures, three issues limit the utility of our findings. First, the selection of possible antecedent variables was limited based on the measures available from the randomized controlled trial. Second, the selection of the eight items used in the index was based on behaviors traditionally classified as sexual-risk behaviors - sexual protective behaviors (such as PrEP use, PEP use, and ART use) were not assessed. Finally, the use of only one study site (Jackson, MS) limits generalizability to other areas of the southern U.S., especially larger metropolitan areas.

\section{Conclusion}

Sexual risk behaviors in a population of YBMSM residing in the southern U.S. are normally distributed. Implications for clinic-based counseling and education programs include a need to "target and tailor" prevention efforts based on the potential use of this scale in clinical settings as well as the several possible antecedents identified in this study. Avoiding sex when partners are intoxicated may be an especially valuable goal of counseling sessions.

\section{Acknowledgments}

This work was supported by the National Institute of Mental Health [5RO1MH092226].

\section{References}

Allen VE, Meyers HF, Ray L. The association between alcohol consumption and condom use: Considering correlates of HIV risk among Black men who have sex with men. AIDS and Behavior. 2015; 19:1689-1700. [PubMed: 25935215]

Benotsch EG, Kalichman S, Cage M. Men who have met sex partners via the Internet: Prevalence, predictors, and implications for HIV prevention. Archives of Sexual Behavior. 2002; 31:177-183. [PubMed: 11974643]

Beyrer C, Baral SD, van Griensven F, Goodreau SM, Chariyalertsak S, Wirtz AL, Brookmeyer R. Global epidemiology of HIV infection in men who have sex with men. The Lancet. 2012; 380(9839):367-377. 
Black AIDS Institute. Back of the line: The state of AIDS among Black gay men in America 2012. Retrieved from: http://www.Blackaids.org/index.php? option=com_content $\&$ view=article $\&$ id=1284\&Itemid=198

Burnham KE, Cruess DG, Kalichman MO, Grebler T, Cherry C, Kalichman SC. Trauma symptoms, internalized stigma, social support, and sexual risk behavior among HIV-positive gay and bisexual MSM who have sought sex partners online. AIDS Care. 2016; 28(3):347-353. [PubMed: 26461452]

Centers of Disease Control and Prevention. HIV among gay and bisexual men, 2015. Retrieved from: http://www.cdc.gov/hiv/group/msm/

Centers of Disease Control and Prevention. DHAP annual report 2011: Accelerating progress, investing for impact. Retrieved from: http://www.cdc.gov/hiv/strategy/pdf/ DHAP_AnnualReport.pdf

Centers for Disease Control and Prevention. HIV/AIDS Surveillance, 2012 (year end edition). US Department of Health and Human Services; Atlanta, GA: Retrieved from: http://www.cdc.gov/hiv/ surveillance/resources/reports/2010report/pdf/ 2010_HIV_Surveillance_Report_vol_22.pdf\#Page=66

Centers for Disease Control and Prevention. HIV/AIDS among African Americans, 2016a. Fact SheetRetrieved from: http://www.cdc.gov/nchhstp/newsroom/docs/factsheets/cdc-hiv-aa-508.pdf

Centers for Disease Control and Prevention. Lifetime risk of HIV diagnosis in the United States, 2016b. Retrieved from: http://www.cdc.gov/nchhstp/newsroom/docs/factsheets/lifetime-risk-hivdx-us.pdf

Chan PA, Towey C, Poceta J, Rose J, et al. Online hookup sites for meeting sexual partners among men having sex with men in Rhode Island, 2013: A call for public health action. Public Health Reports. 2016; 131:264-271. [PubMed: 26957661]

Chesney MA, Koblin BA, Barresi J, et al. An individually tailored intervention for HIV prevention: Baseline data from the EXPLORE study. American Journal of Public Health. 2003; 93:933-938. [PubMed: 12773358]

Crosby, RA., Meyerson, B. STI counseling and condom use instruction: Opportunities for STI clinics. In: Zenilman, J., Shahmanesh, M., editors. Sexually Transmitted Infections and Reproductive Health -- A Guide for Clinicians. Burlington, MA: Jones \& Bartlett Learning; 2009.

Crosby RA, DiClemente RJ, Charnigo R, et al. A brief, clinic-based, safer sex intervention for African American men at-risk of HIV acquisition: A randomized controlled trial. American Journal of Public Health. 2009; 99:S96-S103. [PubMed: 19218185]

Crosby, RA., Salazar, LF., DiClemente, RJ. How theory informs health promotion and public health practice. In: DiClemente, RJ.Salazar, LF., Crosby, RA., editors. Understanding and Changing Health Behavior: A Theory-Based Multidisciplinary Approach. Burlington, MA: Jones \& Bartlett Learning; 2013.

Crosby RA, Milhausen RR, Sanders S, Graham CA, Yarber WL. Being drunk and high during sex is not associated with condom use behaviours: a study of high-risk young Black males. Sexual health. 2014; 11(1):84-86. [PubMed: 24588939]

Jones KT, Gray P, Whiteside YO, Wang T, et al. Evaluation of an HIV prevention intervention adapted for Black men who have sex with men. American Journal of Public Health. 2008; 98:1043-1050. [PubMed: 18445795]

Kalichman SC, Cain D, Weinhardt L, et al. Experimental Components Analysis of Brief Theory-Based HIV/AIDS Risk-Reduction Counseling for Sexually Transmitted Infection Patients. Health Psychology. 2005; 24:98-208.

Keith, TZ. Multiple regression and beyond: An introduction to multiple regression and structural equation modeling. New York, NY: Taylor \& Francis; 2015.

Kelly JA, St Lawrence J, Amirkhanion YA, et al. Levels and predictors of HIV risk behaviors among Black men who have sex with men. AIDS Education and Prevention. 2013; 25:49-81. [PubMed: 23387951]

Kelly JA, St Lawrence J, Tarima SS, et al. Correlates of sexual HIV risk among African American men who have sex with men. American Journal of Public Health. 2016; 106:96-102. [PubMed: 26562130] 
Koblin BA, Mayer KH, Eshleman SH, et al. Correlates of HIV acquisition in a cohort of Black men who have sex with men in the United States: HIV prevention trials network (HPTN) 061. PloS One. 2013; 8(7):e70413.doi: 10.1371/journal.pone.0070413 [PubMed: 23922989]

Laumann, EO., Gagnon, JH., Michael, RT., Michaels, S. The social organization of sexuality: Sexual practices in the United States. Chicago, IL: University Press of Chicago; 1994.

Maulsby C, Millet G, Linsey K, et al. HIV among Black men who have sex with men (MSM) in the United States: A review of the literature. AIDS and Behavior. 2014; 18:10-25. [PubMed: 23620241]

Mayer K, Liang L, Koblin B, et al. Concomitant socio-economic, behavioral, and biological factors associated with the disproportionate HIV infection burden among Black men who have sex with men in 6 U.S. cities. PloS One. 2014; 9(1):e87298. [PubMed: 24498067]

Mimiaga MJ, Reisner SL, Cranston K, et al. Sexual mixing patterns and partner characteristics of black MSM in Massachusettsat increased risk for HIV infection and transmission. Journal of Urban Health. 2009; 86(4):602-23. [PubMed: 19466554]

Mimiaga MJ, Reisner SL, Fontaine YM, et al. Walking the line: stimulant use during sex and HIV risk behavior among Black urban MSM. Drug and Alcohol Dependence. 2010; 110(1-2):30-37. [PubMed: 20334986]

Morgan E, Skaachun B, Michaels S, et al. Marijuana use as a sex-drug is associated with HIV risk among Black MSM and their network. AIDS and Behavior. 2015:1-8. [PubMed: 24668254]

Office of National AIDS Policy. National HIV/AIDS strategy for the United States. 2010. Retrieved from: http://www.whitehouse.gov/administration/eop/onap/nhas

Noar SM, Benac CN, Harris MJ. Does tailoring matter? Meta-analysis of tailored print health behavior change interventions. Psychological Bulletin. 2007; 133:673-693. [PubMed: 17592961]

Nöstlinger C, Platteau T, Bogner J, et al. Implementation and operational research: Computer-assisted intervention for safer sex in HIV-positive men having sex with men: Findings of a European randomized multi-center trial. JAIDS. 2016; 71:e63-e72. [PubMed: 26866955]

Office of National AIDS Policy. National HIV/AIDS strategy for the United States: Updated to 2020. 2015. Retrieved from: https://www.aids.gov/federal-resources/national-hiv-aids-strategy/nhasupdate.pdf

Safren SA, O’Cleirigh CM, Skeer M, Elsesser SA, Mayer KH. Project enhance: A randomized controlled trial of an individualized HIV prevention intervention for HIV-infected men who have sex with men conducted in a primary care setting. Health Psychology. 2013; 32(2):171. [PubMed: 22746262]

Salazar, LF., Crosby, RA., DiClemente, RJ., Noar, SM. Health communication theory, social marketing, and tailoring. In: DiClemente, RJ.Crosby, RA., Salazar, LF., editors. Understanding and Changing Health Behavior: A Theory-Based Multidisciplinary Approach. Burlington, MA: Jones \& Bartlett Learning; 2013. p. 187-210.

Sifakis F, Hylton JB, Flynn C, Solomon L, MacKellar DA, Valleroy LA, et al. Prevalence of HIV infection and prior HIV testing among young men who have sex with men. The Baltimore young men's survey. AIDS and Behavior. 2010; 14:904-912. [PubMed: 17968648] 


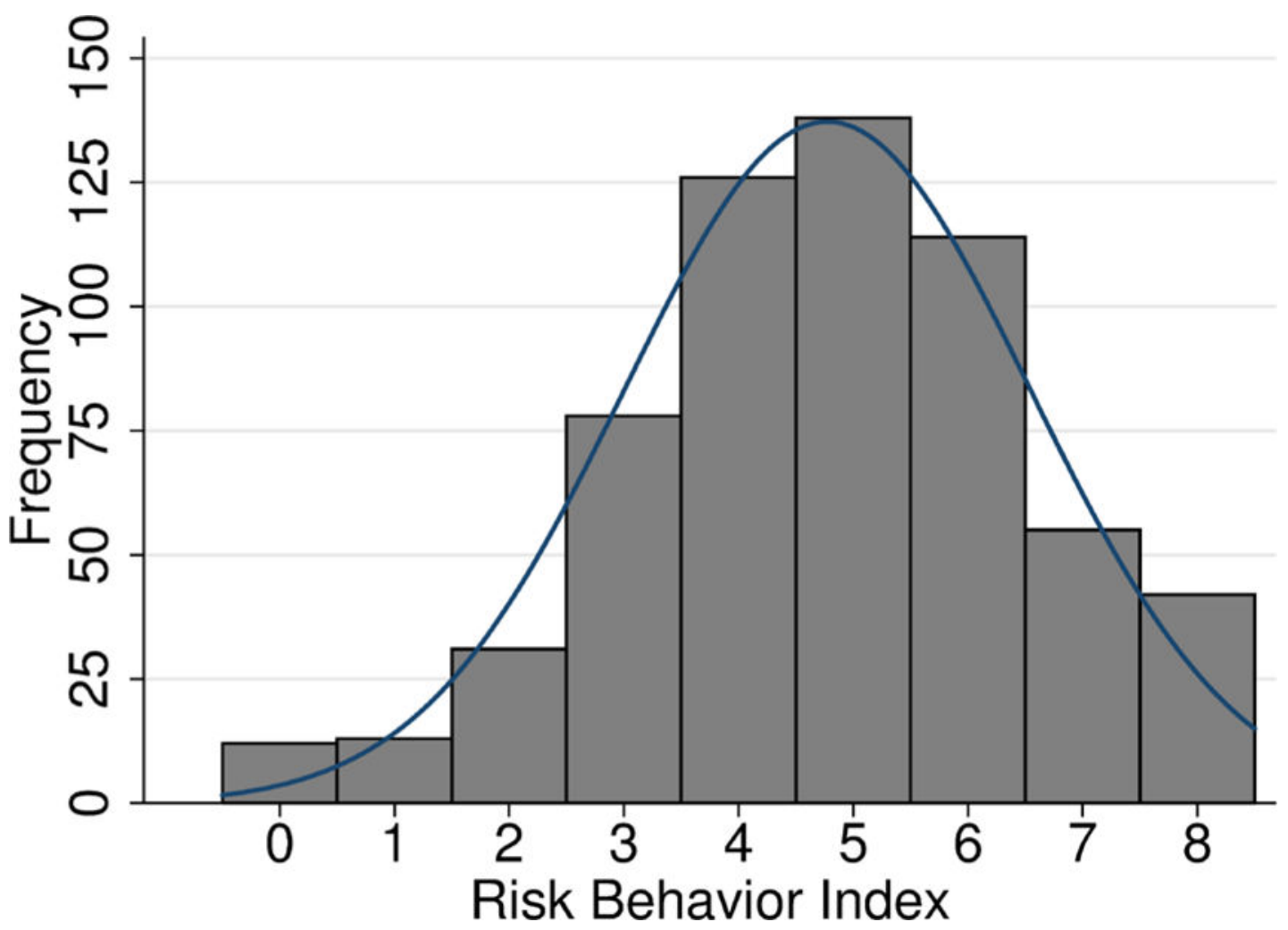

Figure 1.

Distribution of sexual risk behavior index score among young Black MSM 


\section{Table 1}

Items comprising the index measure of sexual risk and descriptive statistics for each item (all items are for a 90-day recall period)

\begin{tabular}{ll} 
Item & $\mathbf{n} / \mathbf{N}(\boldsymbol{\%})$ \\
Had anal sex with male partner & $515 / 600(86.0)$ \\
1 or more male sex partners, as a top & $456 / 594(76.7)$ \\
1 or more male sex partners, as a bottom & $432 / 597(72.3)$ \\
Any condomless anal sex as a top & $149 / 542(24.5)$ \\
Any condomless anal sex as a bottom & $152 / 431(35.2)$ \\
Any condomless oral sex & $429 / 526(81.5)$ \\
New anal sex partner as a top & $396 / 609(65.0)$ \\
New anal sex partner as a bottom & $379 / 609(62.2)$ \\
\hline
\end{tabular}




\section{Table 2}

\section{Bivariate Associations Between An Index of Sexual Risk Behaviors and Possible Antecedents of Increased} Risk Among Young Black MSM

\begin{tabular}{|c|c|c|c|c|}
\hline Outcome & Mean & $t$ & df & $p$ \\
\hline Average monthly income $<\$ 1,000$ & & 1.78 & 597 & .08 \\
\hline Yes $(46.1 \%)$ & 4.64 & & & \\
\hline No & 4.89 & & & \\
\hline Currently receiving welfare & & 1.98 & 607 & .048 \\
\hline Yes $(8.2 \%)$ & 4.30 & & & \\
\hline No & 4.82 & & & \\
\hline Depend on sex partners for money etc. & & 2.20 & 590 & .03 \\
\hline Yes $(13.5 \%)$ & 5.24 & & & \\
\hline No & 4.79 & & & \\
\hline High school education or less & & 2.05 & 607 & .04 \\
\hline Yes $(40.2 \%)$ & 4.60 & & & \\
\hline No & 4.90 & & & \\
\hline Currently enrolled in a school & & .08 & 607 & .94 \\
\hline Yes & 4.78 & & & \\
\hline No $(52.7 \%)$ & 4.76 & & & \\
\hline Currently member of a gay family & & .58 & 607 & .56 \\
\hline Yes & 4.71 & & & \\
\hline No $(67.8 \%)$ & 4.81 & & & \\
\hline Never attend religious services & & .87 & 607 & .43 \\
\hline Never attend $(17.3 \%)$ & 4.63 & & & \\
\hline Attend & 4.80 & & & \\
\hline Sex with females & & 4.68 & 607 & $<.001$ \\
\hline Yes $(19.7 \%)$ & 4.11 & & & \\
\hline No & 4.94 & & & \\
\hline Meeting sex partners online & & 3.43 & $602.2^{*}$ & .001 \\
\hline Yes $(44.2 \%)$ & 5.04 & & & \\
\hline No & 4.56 & & & \\
\hline Used marijuana "right before sex" & & 3.43 & 607 & .001 \\
\hline Yes $(33.7 \%)$ & 5.12 & & & \\
\hline No & 4.60 & & & \\
\hline Used any illegal drug/substance before sex & & 2.13 & 607 & .03 \\
\hline Yes $(74.2 \%)$ & 4.86 & & & \\
\hline No & 4.52 & & & \\
\hline Drunk while having sex & & 4.39 & 607 & $<.001$ \\
\hline Yes $(29.3 \%)$ & 5.23 & & & \\
\hline No & 4.57 & & & \\
\hline Partners(s) drunk while having sex & & 5.17 & 594 & .001 \\
\hline Yes $(46.5 \%)$ & 5.23 & & & \\
\hline
\end{tabular}




\begin{tabular}{lllll}
$\begin{array}{lll}\text { Outcome } \\
\text { No }\end{array}$ & $\begin{array}{l}\text { Mean } \\
4.52\end{array}$ & & df & $\boldsymbol{p}$ \\
\hline
\end{tabular}

* Due to lack of homoscedasticity, an unequal variance methods was used, yielding an adjusted value for degrees of freedom 


\section{Table 3}

Adjusted Beta Estimates of Possible Antecedents Retained in a Hierarchical Multiple Linear Regression Model and Significance of Interactions with HIV Status

\begin{tabular}{lll} 
& $\beta / \mathbf{t}(\boldsymbol{p})$ & Int. HIV $\left.\mathbf{l}^{\mathbf{p}}\right)$ \\
High school education or less & $-.09 / 2.19(.03)$ & .18 \\
Depend on sex partners for money etc. & $.08 / 1.89(.06)$ & .17 \\
Average income $<\$ 1,000$ per month & $-.08 / 1.87(.06)$ & .004 \\
Sex with females & $-.11 / 2.69(.007)$ & .16 \\
Meeting sex partners online & $.08 / 2.06(.04)$ & .82 \\
Partners(s) drunk while having sex & $.19 / 4.63(<.001)$ & .15 \\
\hline
\end{tabular}

${ }^{1}$ Interaction terms with HIV status 